\title{
EDITORIAL
}

\section{Embedding patient voices in CMAJ}

\author{
Victoria Saigle MSc, Jean Miller PhD BScN, Vincent Dumez MSc, Kirsten Patrick MBBCh MSc
}

Cite as: CMAJ 2021 July 12;193:E1046-7. doi: 10.1503/cmaj.211092

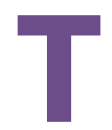

he CMAJ Group has long recognized the importance of patient engagement in the generation of medical knowledge. ${ }^{1-3}$ Over the past year, with our patient partners, we have developed policies and best practices with the goal to embed patient voices in journal governance and to bring patients' perspectives to more articles.

This issue highlights the engagement of patient partners in research, ${ }^{4,5}$ the development and delivery of patient-centred health policy, ${ }^{6,7}$ the importance of understanding patient and caregiver experiences, ${ }^{8}$ and practical information relevant to patients managing their conditions at home. ${ }^{9} \mathrm{CMAJ}$ has adopted the Canadian Institutes of Health Research definition of patients as people with lived experience of a health condition, which includes patients themselves and their families and informal caregivers (https://cihr-irsc.gc.ca/e/48413.html\#a4).

Health conditions do not occur in isolation. People manage their health conditions in the context of their lives and in so doing gain expertise in living with them. In recent years, patients' expertise has helped shape research by identifying important outcomes not previously considered when measuring the success of new treatments (e.g., fatigue in people with rheumatoid arthritis ${ }^{10}$ ) and barriers to accessing health care or treatment (e.g., lack of transportation and inconvenient dosing schedules for medications). Furthermore, community-led initiatives have informed health system strategies that are acceptable and culturally relevant. ${ }^{11}$ Collaborative patient-partnered teams are addressing care issues of concern to both the health system and patients, such as patients' need for support for selfmanagement, and developing centralized intake processes and tools that, while addressing the needs of patients, have also improved the system. ${ }^{12-14}$

When engaging patients, it is important to pay attention to who is involved. Some patients may feel that they can share their perspectives only when invited to do so, as shown by articles in this issue. ${ }^{7,8}$ People who experience discrimination or stigma and marginalized groups are less likely to share their opinions with the health care system or be involved in engagement activities. Factors such as familiarity with health care or research processes, education, the financial ability to participate without compensation, trust in the health care system and time constraints will limit whose perspectives are heard. This is something we will be monitoring internally as
CMAJ continues developing our own initiatives for patient engagement.

In the last year we have embedded patient partners in CMAJ's governance by including patients in our advisory groups to co-create policies and inform priorities for content generation, and supported patients as authors and peer reviewers. This is ongoing. Concrete steps to date include developing compensation policies for our partners, simplifying and adding flexibility to procedures, such as manuscript submission, and developing mechanisms to evaluate our initiatives for patient engagement over time.

This themed issue sees the launch of a new type of article in the Practice section - 360 Cases. These articles will highlight the interpersonal and systemic aspects of health care that are seldom discussed in other Practice articles in CMAJ. ${ }^{8}$ Each 360 Case will comprise a brief case summary and personal reflections from 2-4 people involved in a clinical encounter; 1 of the authors will always be a patient, family member or caregiver. Authors' reflections will highlight a variety of perspectives related to a shared health care encounter.

Patient engagement is not a fad or a trend. It brings unique perspectives to health care. It promotes collaboration, communication and ethical practice, and it anchors practice firmly in stories of lived experience that are rich in learnings. But, beyond stories, patient perspectives bring a better understanding of the health care system to professionals who are often locked in their operating silos. Patients speak and think in terms of "life trajectories," whereas health care providers often think in terms of single clinical encounters. Patients naturally mobilize their communities and act as agents of influence in civil society. They bring specific knowledge and skills that are necessary to innovation in medical practice. This is why patient involvement in CMAJ is essential.

Embedding patient voices in CMAJ's operations will require iterative development. We believe it will have lasting benefits for our readers, practising clinicians, the Canadian public, researchers and Canada's health care system. For readers who are new to patient engagement, we hope this themed issue will provide insight into some of the many ways that involving patients can improve health care. Readers can review our Statement of Purpose for patient engagement at https://www.cmaj.ca/ statement-purpose-patient-engagement. 


\section{References}

1. Patrick K. Realizing the vision of patient-relevant clinical research. CMAJ 2016;188:1063.

2. Patrick K, Kebbe M, Aubin D. A home for patient-oriented research. CMAJ 2018;190:E607.

3. Laupacis A. CMAJ priorities for 2020. CMAJ 2019;191:E1344.

4. Campbell RB, Larsen M, DiGiandomenico A, et al. The challenges of managing diabetes while homeless: a qualitative study using photovoice methodology. CMAJ 2021;193:E1034-41.

5. Nykiforuk $\mathrm{CIJ}$. Engaging patients in research using photovoice methodology. CMAJ 2021;193:E1050-1.

6. Denegri S, Starling B. COVID-19 and patient engagement in health research: What have we learned? CMAJ 2021;193:E1048-9.

7. Buchanan F. How are we going to do this? CMAJ 2021;193:E1052-3.

8. Oxland PR, Barnes SL, Cottrell T, et al. End of life: from chronic rhinosinusitis to a late diagnosis to intensive care. CMAJ 2021;193:E1042-4.

9. Mostarac I, Thomas J, Atzema C. Monitoring blood pressure at home: guidance for Canadian patients. CMAJ 2021;193:E1045.

10. de Wit M, Abma T, Koelewijn-van Loon M, et al. Involving patient research partners has a significant impact on outcomes research: a responsive evaluation of the international OMERACT conferences. BMJ Open 2013;3:e002241.

11. Bharadwaj L. A framework for building research partnerships with First Nations communities. Environ Health Insights 2014;8:15-25.

12. Marlett N, Shklarov S, Marshall D, et al. Building new roles and relationships in research: a model of patient engagement research. Qual Life Res 2015;24:1057-67.

13. Carr ECJ, Patel JN, Ortiz MM, et al. Co-design of a patient experience survey for arthritis central intake: an example of meaningful patient engagement in healthcare design. BMC Health Serv Res 2019;19:355.

14. Mrklas KJ, Barber T, Campbell-Scherer D, et al. Co-design in the development of a mobile health app for the management of knee osteoarthritis by patients and physicians: qualitative study. JMIR Mhealth Uhealth 2020;8:e17893.

\section{Competing interests: https://www.cmaj.ca/page/staff}

Affiliations: Ottawa Hospital Research Institute (Saigle), Ottawa, Ont.; Patient and Community Engagement Research (PaCER) Program (Miller), Faculty of Medicine, University of Calgary, Calgary, Alta.; Directeur des Partenariats Communautaires (Dumez), Faculté de médecine, Université de Montréal; Centre d'excellence sur le partenariat avec les patients et le public (Dumez), Faculté de médecine, Université de Montréal, Centre de recherche du CHUM, Montréal, Que.; Unité de soutien SRAP du Québec, Longueil, Que.; Réseau Québécois COVID - Pandemie (Dumez); Lead, Patient involvement, CMAJ (Saigle); Interim Editor-in-Chief, CMAJ (Patrick)

Content licence: This is an Open Access article distributed in accordance with the terms of the Creative Commons Attribution (CC BY-NCND 4.0) licence, which permits use, distribution and reproduction in any medium, provided that the original publication is properly cited, the use is noncommercial (i.e., research or educational use), and no modifications or adaptations are made. See: https://creativecommons.org/ licenses/by-nc-nd/4.0/

Correspondence to: CMAJ editor, editorial@cmaj.ca 